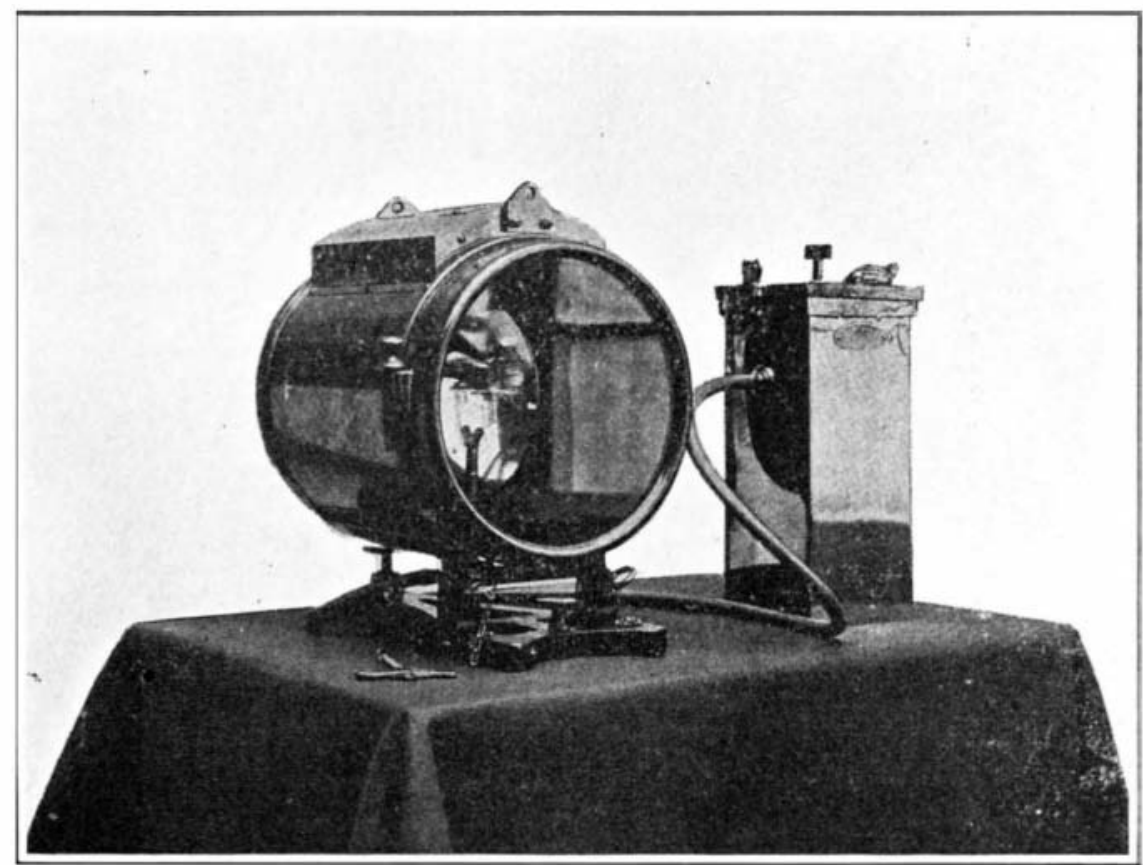

Fig. 1.-Large Acetylene Signal Lamp.

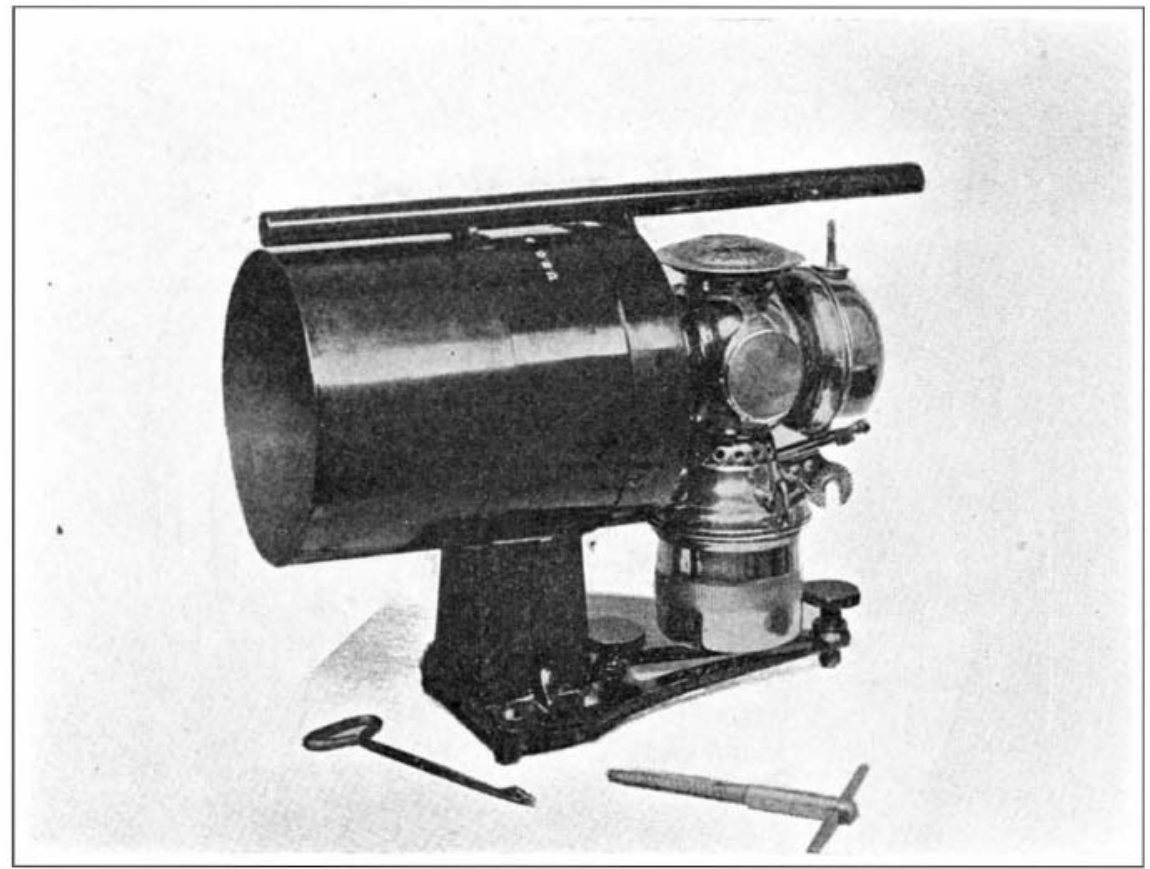

Fig. 2.-Small Acetylene Signal Lamp.

\title{
The Texas-California Arc of Primary Triangulation*
}

\section{Obtaining Fundamental Data for a Geodetic Survey of the United States}

By William Bowie, Inspector of Geodetic Work and Chief of the Computing Division, Coast and Geodetic Survey

GENERAL BTATEMENT.

IN September, 1907, the Coast and Geodetic Survey began the reconnoissance (selection of stations) for an are of primary triangulation to extend westward from the line Kyle-McClenny of the ninety-ighth meridian the line Kyle-McClenny of the ninety-eighth meridian Jacinto of the Pacific coast primary triangulation in the

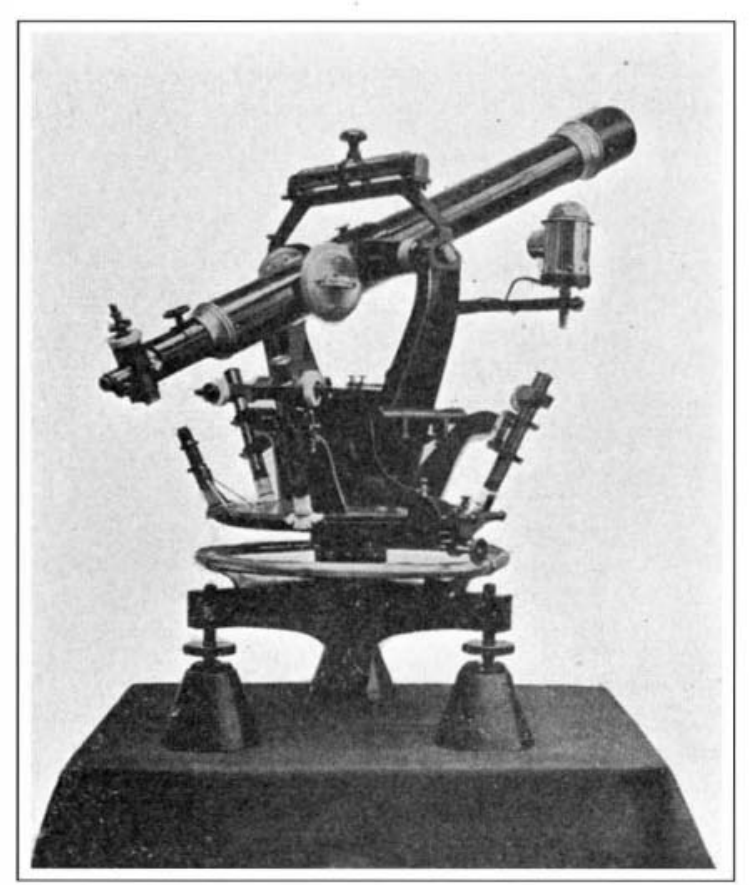

liig. 3.-Twelve-inch Theodolite With Electric Light for Illuminating the Cross Wires.

southern part of California. The reconnoissance was ended in February, 1908. The erection of signals was begun at the eastern end of the are immediately after the completion of the reconnoiseance, and the observing began in the foll of 1908 . The observing was done in three seasons and was completed in February; 1911. The observing party also measured the bases to control the lengths in the triangulation. and it observed suc astronomic azimuths as were needed along this are for geodetic purposes.

The length of the primary triangulation of this arc along the axis of the scheme, is 1,207 miles $(1,942$ kilometers), and the length of subsidiary schemes, secondary in character, is about 70 miles (113 kilometers) The latitudes of the two stations already established in Texas from which the are started are $32 \mathrm{deg} .49 \mathrm{~min}$. and $32 \mathrm{deg}$. $27 \mathrm{~min}$. The latitudes of the two old stations in California to which the new work was joined are 32 deg. 57 min. and $33 \mathrm{deg} .49 \mathrm{~min}$. In longitude the arc extends from $98 \mathrm{deg}, 12 \mathrm{~min}$. to $116 \mathrm{deg} .41 \mathrm{~min}$. The range in latitude is $3 \mathrm{deg}$. $58 \mathrm{~min}$. The area in the main scheme is 49,220 square statute miles.

- Special Publication No. 11 of the Coast and Geodetic Survey.
There were 115 stations occupied for horizontal observations, 92 in the main scheme and 23 in the subsidiary schemes.

The Texas-California arc has been completed with greater rapidity and at a lower cost than any previous are of primary triangulation in this country. It probably has not been excelled in rate of progress or low unit costs in any other country.

$$
\text { RECONNOISBANCE. }
$$

The reconnoissance was done in one single season by a single party, which consisted of the writer, who was in charge; Signalman Jasper S. Bilby, who bad previously had much experience in reconnoissance for primary triangulation, and a teamster. The equipment of the party consisted principally of five horses and mules, one freight wagon, one spring wagon, two riding saddles, two 9-foot center-pole tents, bedding for three men, a small amount of supplies and tools for making repairs, two draw telescopes, several binoculars and prismatic pocket compasses, a pocket tape line, a 4-inch transit with vertical circle, an odometer, and a small case of drawing instruments. an odometer, and a small case of drawing instruments. commerical maps were procured, as well as all available data relating to previous surveys in or near the area to be covered by the reconnoissance.

It was planned that the new triangulation should extend from a line of the ninety-eighth meridian primary triangulation, just to the westward of Weatherford, Tex. follow the Texas \& Pacific Railroad to El Pasco, Tex.; eross the southern parts of New Mexico and Arizona as close as practicable to the international boundary, and then cross the State of California and connect with a line of the Pacific coast triangulation to the eastward of San Diego.

It was also planned that the new work should connect with existing triangulation by the United States Geological Survey, the California and Nevada boundary survey, the United States and Mexican boundary survey, and with monuments of the international boundary at El Paso, Tex., Nogales and Yuma, Ariz., and at other places where practicable.

The first 330 miles at the eastern end of the are runs through a partly wooded, rolling country, with an occasional isolated butte or hill (usually flat topped). In this section it was necessary to elevate the instrument at most of the stations. To the westward of the stations Ingle and Sist the country was mountainous and no structures

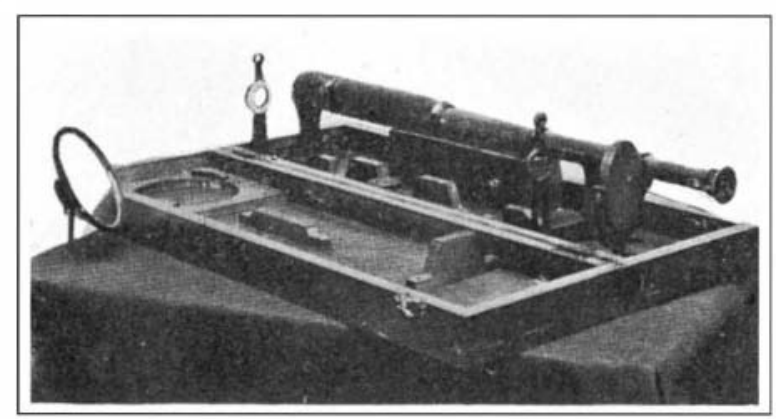

Fig. 5.-Box Heliotrope Used on Primary Triangulation. wcre needed for elevating the instrument except at the Deming base.

During the first part of the season the party remained together and the writer and Mr. Bilby went out from the cimp together to nearly all of the selected stations. During the greater part of the season the party operated in two separate sections; the writer, with a saddle horse,

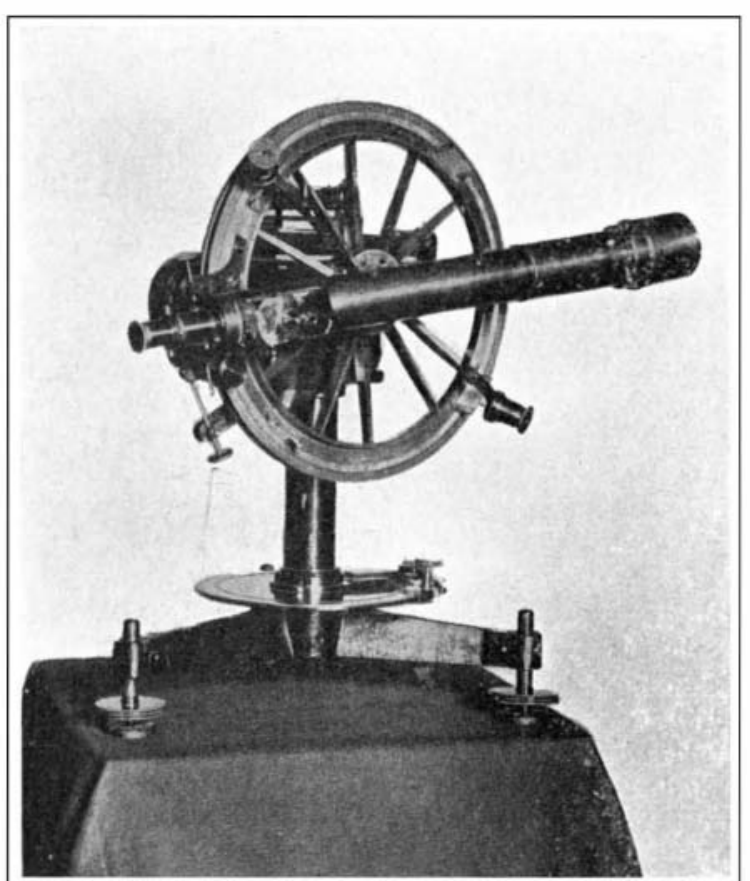

kig. 4.-Vertical Circle I'sed in Trigonometric Leveling and for Making Time Observations.

teamster, and freight wagon, while Mr. Bilby used a spring wagon. After dividing, the party met only at Sierra Blanca, Tex.; El Paso, Tex.; Hermanas, N. Mex.; Tucson, Ariz.; and Yuma, Ariz. At each of these places the scheme was adopted from the stations located by the two observers.

No day or night signals of any kind were used during the attested by the fact that no reconnoissance station was abandoned during the subsequent triangulation. One station was moved about one half mile on a flat-topped ridge in order to avoid elevating the instrument 16 feet, and the north end of the Deming base line was moved northward about 2 miles to improve the base net In only a few cases was it necessary to elevate the instruonly a few cases was it necessary to elevate the

In the following table are given in condensed form the data regarding the progress and cost of the reconnoissance for the Texas-California anc. The cost includes all salaries, even that of the chief of party while at the office preparing for field work and after his return from the feld while making out his final report on the recomn the feld while making out his final report on the reconnoissance. The cost also includes 25 per cent of the cost of five horees and mules and two wagons which were used 
about twenty months on this are by the building and observing parties and only about five months by the reconnoissance party. In this table only the stations, the area, and the length of the main scheme are considered, although subsidiary stations located added to the total cost of the season.

STATISTICS OF RECONNOISSANCE.

Date of beginning actual field operations. . Sept. 17, 1907 Date of ending actual field operations.......Feb. 8, 1908 Date of ending actual field operations........Feb. 8,1908 $\begin{array}{lr}\text { Total length of season by months......... } & 4.07 \\ \text { Cost of work, including salaries.......... }\end{array}$ Cost of work, including salaries...........
Number of principal stations selected..... Length of main scheme in miles. . . .

A

progress............... $\$ 4.02$

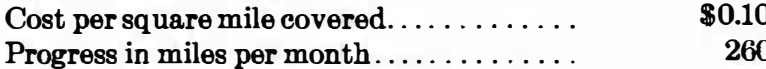

SIGNALS.

The signals used on the Texas-California triangulation were similar to those used on the greater portion of the ninety-eighth meridian triangulation, which are described in detail in Appendix 4 of the Report for 1303 . Fig. 6 is taken from that report. When only one observing party is operating, as was the case on the TexasCalifornia arc, the top platform shown on the signal in Fig. 7 is omitted. The superstructure shown on the signal in illustration Fig. 6 is used to elevate the heliotrope and lamp at each end of an obstructed line. Signals at nearly all of the stations occupied during the first season were erected during the spring and fall of 1908 and before the beginning of the observing. Several signals were erected just before the close of the first observing season.

During the spring of 190836 signals of an aggnegate height of 1,015 feet (309 meters) were erected at a total cost of $\$ 3,600$. This includes the material for station and reference marks and the cost of putting them in place. This made the cost per vertical foot $\$ 3.55$. PROGRESS OF OBSERVING. Season of 1908-9.

In addition to the chief, the observing party during the first season consisted of Signalman Bilby, a recorder and a teamster. The camp equipage and means of transportation were practically the same as were used in the reconnoissince. With a light outfit quick moves could be made between stations, and the work about camp was reduced to a minimum. The members of the observing party lived in the tents and, wherever practicable, obtained board at farm and ranch houses. Where this was not convenient, a small emergency cooking outfit was used by the party in preparing meals.

The observing was done entirely on heliotropes and acetylene signal lamps. The usual form of heliotrope is shown in Fig. 5. The lamp used on most of the TexasCalifornia triangulation is shown in illustration Fig. 1. The smaller lamp, used on nearly all the ninety-eighth meridian trisngulation and at a few stations of the new triangulation, is that shown in illustration Fig. 2.

Five light keepers were used by the triangulation party, and they were directed by letter and by code signals, sent in a.modified Morse alphabet, using the lamps and heliotropes in signaling. The light keepers lived in tents, prepared their own meals, and moved from station to station with teams hired for the individual trips. Each was supplied with a sketch of the triangulation and also with descriptions of the stations. They had no difficulty in moving from station to station, and only in rare instances did they have any trouble in getting the direction to the observer's station. With few exceptions, the sam men were retained as light keepers throughout the sea son. It is essential to rapid progress to have a trained corps of light keepers who can operate without assistance from the observing party.

The country traversed during the first season was rolling, with occasional hills standing well above the general level of the country. The average length of the lines of the triangulation was about 15 miles (24 kilometers). The land was partially settled and the roads were fair. Very little difficulty was encountered in getting water for the party and stock.

\section{Season of 1909-10.}

The second season's observing began on September 7th, 1909, at the station Toyah, Tex., and ended at the Deming base net, New Mexico, on January 7th, 1910. Owing to the fact that the country to be worked over wa arid, mountainous, and with few settlers, a somewhat different organization of party was used during this

The observing party consisted of the chief (who was the observer), a recorder, and a teamster. The camp equipage was reduced to a minimum. Seven heliotropers or light keepers -were employed throughout the season. They were usually posted by the signalman and his assistant, who also prepared the stations for the observer and set the station marks. When a light keeper took a station he remained there until all observations on that station were completed. He was also at the station and assisted the observing party while the station was occupied for observations. The movements of the light keepers were, as usual, directed by signaling. When each of the light keepers was through with his work at a station he wa moved to the nearest railroad station by a teamster, who was employed throughout the season for that purpose, and the light keeper traveled by train ahead of the observer and was posted as noted above. The teamster,

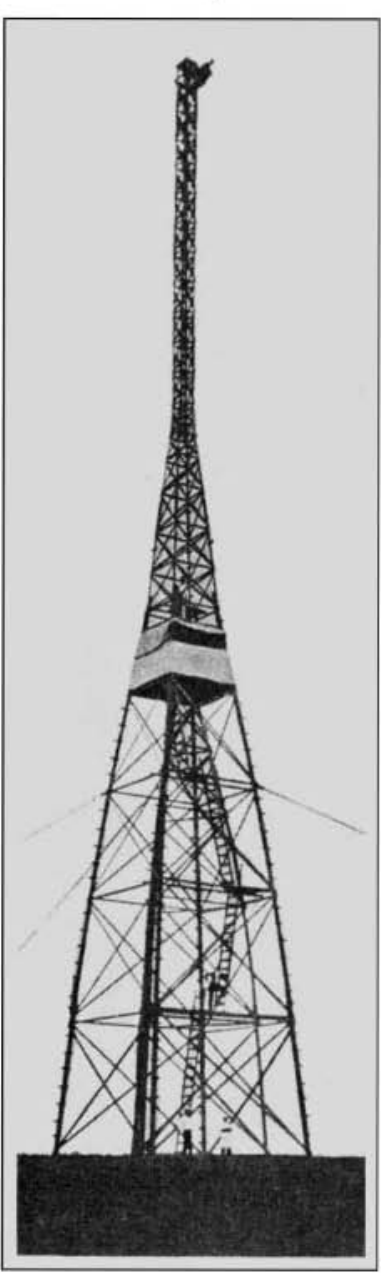

Fig. t.-Signal at Burson on the Ninety-eighth Meridian Triangulation.

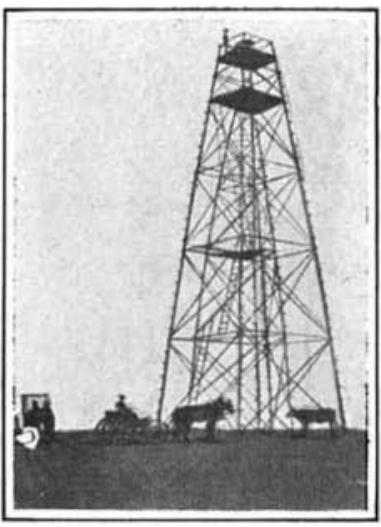

FIg. 7.-Sixty-foot Signal. whose work it was to move the rear light keepers to the railroad, usually communicated with the men on the mountain peaks by signaling with a heliotrope or lamp.

It was found to be necessary in most cases to haul water to the stations for the light keepers. As a rule, when he was posted, enough could be taken to a station to last until the observing party reached the station. Each of the several freight wagons was equipped to carry about 70 gallons of water in specially constructed cans. These cans were fastened to the outside of the wagon.

The camp equipage of the observing party and of the light keepers was taken to the station, or some point near it, by pack mules or horses. It was only occasionally that any hand packing was done.

At the end of the season the party measured the Deming base with invar tapes.

$$
\text { Season of 1910-11. }
$$

At the close of the second season's work there remained to at the eastern end of this section in New Mexico and Arizona are on high mountain peaks, and the three stations at the extreme western end of the section are also on high mountains. It was desired that all of this section be done in one observing season, and in order to do this the high mountain stations must be occupied during the summer months in order to avoid the snows of the early fall. The plan adopted and carried out was to complete the observations first at the stations forming the extreme western quadrilateral of the arc, then return to the vicinity of the Deming base net and work westward through the remainder of the scheme. The last one of the high peaks (Catalina) was occupied on November 1st. The observations for this season began on July 6th, 1910 , and they ended on February 22nd, 1911. Neither the observing party not the light keepers were seriously interfered with by snow during the season.

The organization and equipment of the party were the same as those of the preceding season and the management of'the work was not changed in any material way. METHODS OF OBSERVING EMPLOYED.

The observations for the primary horizontal angles were made in accordance with the General Instructions for Primary Triangulation.

All the horizontal angle measures were made by the direction method, using the 12-inch (30-centimeter) theodolites made in the Instrument Division of the Survey, one of which is shown in Fig. 6. The telescope used has a clor aperture 61 millimeters and its focel longth is 74 centimeters. The circle is graduated to five-minute is 74 centimeters. The circle is graduated to five-minute spaces and is

The telescope of the theodolite has two parallel vertical wires, about 20 seconds apart, for making the pointings for horizontal angles. The results from a number of seasons' work indicate that this arrangement of the wires in the telescope is more satisfactory than either the single vertical wire or the oblique cross. The double wire is especially effective when the image of the light or heliotrope is large and unsteady.

In making the measurements of horizontal directions each direction in the main scheme was measured 16 times. A direct and reverse reading was considered one measurement, and 16 positions of the circle were used.

When a broken series was observed, the missing signals were observed later in connection with the chosen initial or with some other one, and only one, of the stations

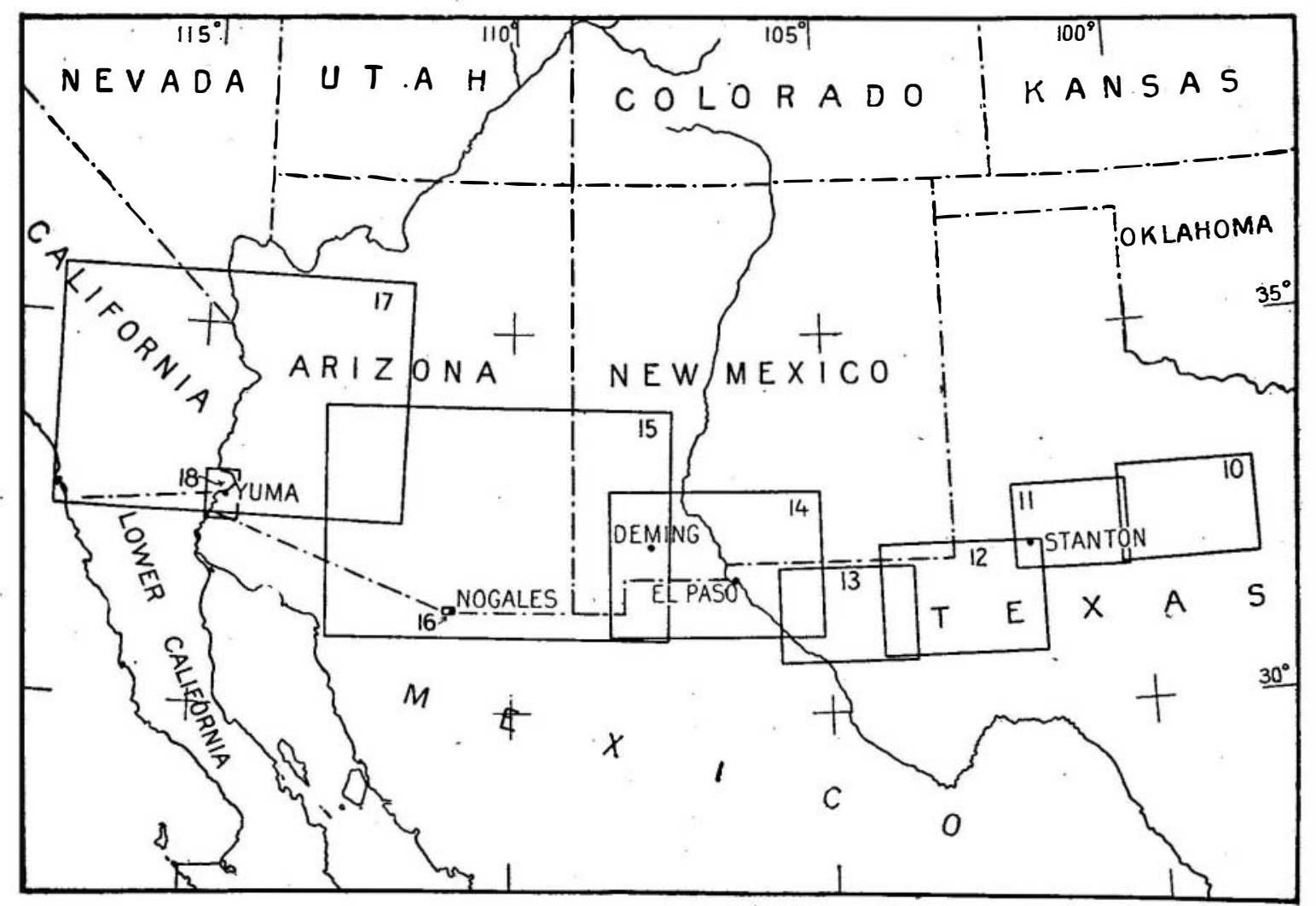

Fig. 8.-Index Map of the Territory Traversed. 
already observed in that series. With this system of observing no local adjustment was necessary. Little time was spent in waiting for the doubtful signal to show. If it was not showing within, say, one minute of when
wanted, the observer passed to the next. A saving of time results from observing many or all of the signals in each series, provided there are no long waits for signals to show, but not otherwise.

In selecting the conditions under which to observe primary directions the observer proceeded upon the assumption that the maximum speed consistent with the requirement that the closing error of a single triangle in the primary scheme shall seldom exceed tbree seconds, and that the average closing error sball be but little greater than one second, was what was desired rather than a greater aceuracy than that indicated with slower progress. This standard of accuracy used in conneetion with other portions of the general instructions defining the necessary strength of figures and frequency of bases line, as computed from an adjacent base, is about 1 part in 88,000 and that the actual discrepancy between bases is always less than 1 part in 25,000 .

The limit for rejection of observations upon direetions in the main scheme was 5 seconds from the mean. No observation agreeing with the mean within this limit was rejected unless the rejection was made at the time of taking the observation and for some other reason than was substituted for the rejected one before leaving the station, if possible, without much delay.

The number of observations at supplementary stations and on intersection stations, as well as the number of vertical angle observations, conformed to the require ments of the General Instructions. It is not necessary to specify them here.

CONNECTIONS MADE WITH STATIONS PREVIOUSLY ESTABLISHED.

The Texas-Californis primary triangulation connected with the triangulation of the United States Geological Survey near the eastern end of the are on stations Hitson, Wasp, Abilene standpipe, and Cisco astronomic station; also in western Texas at stations Newman, Diablo, Quitman, Cerro Alto, and North Franklin; in New Mexico on stations Line and Corduna; in Arizona with stations Graham, Baldy, Benedict, Huachuca, Mule, Burro, Superstition, and Maricopa northwest base; and in California with stations American and Picacho.

Connections were made with the triangulation of the United States and Mexican Boundary Survey at El Paso, Nogales, and Yuma. Besides the monuments at each of those three places, international monuments Nos. 31, 32 39,40 , and 91 were connected with the triangulation.

A connection with the triangulation of the CaliforniaNevada boundary was made near Needles, Cal.

Investigations of Chemical Reactions at High Pressures

By the Berlin Correspondent of the Scientific American

ThE application of bigh pressures must influence the course of chemical reactions in a number of ways. In gaseous systems increased pressure brings with it in creased concentrations, and hence increased reaction velocity. At the same time the point of equilibriumis in general changed in favor of the formation of the products having a smaller volume. In the case of liquid reagents one of the most important effects of high pressure is to render available high temperatures, owing to the rise in boiling point with pressure.

Dr. F. Bergius', lecturer at the Hanover Technical University, has perfocted an apparatus which, though comprising more than ten joints and closures, allows a pressure of 150 atmospheres to be kept up for 20 days a temperatures of upward of $300 \mathrm{deg}$. Cent. With this apparatus he, for instance, investigated the decomposition of calcium peroxide, and succeeded in producing this compound by synthesis from lime and oxygen.

With a similar apparatus he, in conjunction with his assistant, Mr. Spech, then investigated some reactions of water heated far beyond its ordinary boiling point. H was thus in a position to show the possibility of burning carbon with liquid water heated close to its critical poin about 360 deg. Cent.), thus forming carbonic acid and hydrogen. The water, containing in solution various catalyzers, was made to act on charcoal or coke in an iro bomb, which, being covered with an oxide layer, was not affected by the water. The hydrogen and carbonic acid thus obtained by combustion were found to bear to on another a ratio approximately corresponding to theory.

In other experiments the water heated beyond its boiling point was not itself one of the re-agents but, as it were, served as heat accumulator. These interesting experiements were intended to reproduce the naturel process of coal formation. If certain organic materials such as wood, peat, etc., be heated to charring in an airtight vessel, the temperature rises spontaneously above that of the external source, the decomposition of cellu1 Zeitachr. 1. Elektrochemie, No. 15, 1912 . lose being attended by production of heat. This is why all previous attempts in this direction failed to produce coal of the same composition as pit coal, the spontane
heating resulting in a partial coking of the materials.

If we wish to produce in our laboratories in a short
If we the time and at high temperatures the same process as carried out by Nature in millions of years at ordinary temperatures, means should be provided to remove any excess of heat from the point of reaction. Liquid water in intimate contact with the substance to be charred was found to provide the means for such regulation of tem perature. Owing to its high heat capacity, water absorb any surplus heat produced in the disaggregation of cellulose. Peat heated in high pressure vessels in its natural condition, i. e., with 85 per cent of water, or else pure cellulose mixed with much water, was used in these experiments. The gases evolved in the charring process which consist of carbonic acid and methane, containin about 12 per cent of the total carbon, were analyzed after the experiment. The coal products obtained at different temperatures and after more or less prolonged reaction were found to be of extremely variable composition. The higher the temperature, the more oxygen was evolved in the form of carbonic acid, and the greate were the carbon contents of the artificial coal. The com position of the eoal obtained at $340 \mathrm{deg}$. Cent. coincides with that of natural fat coa

As in most reactions it was found that the velocity of this reaction approximately doubled for every $10 \mathrm{deg}$. Cent. rise in temperature. Thus for an increase of 30 deg. Cent, the reaction velocity would be multiplied $2^{3}=8$ times. This allows us to form some estimate of the time which would have been required for producing the same coal at the temperature of the ground. Sup posing the average temperature of natural coal formation to be in first approximation $10 \mathrm{deg}$. Cent., a period of about 7 to 8 million years would, it is found, have been required to produce natural fat coal. This figure agree required to produce natural fat coal. This

\section{China Suppressing the Opium Habit}

THE establishment of the Chinese Republic has led many occidentals to change their settled opinion as to which they supposed characteristic of the inhabitant of the Celestial Empire. There is another story of accomplishment in China, however, during the past five years, which makes it even clearer than the recent revolution that there are undreamed of springs of energy in the character of the Chinese people. About five years ago the Chinese government decided that opium-smoking, which had become the national vice of China even to a greater extent than alcoholism is of the Western nations, must stop, and that within ten years. It is scarcely to be wondered at that when this government edict was issued it was greeted with smiles everywhere; ten years seemed entirely too short a period to set for any such reformation, at least two or three generations appearing more reasonable. Scarcely any one dared to hope for success and it seemed beyond all doubt that China had entered on an impossible task. Five years have passed of the ten-year period, and now the world knows that China has already achieved great things and that success in the great national crusade seems almost assured.

The method that China is pursuing will interest particularly those who are concerned with similar problems of the abuse of stimulants and narcotics and who are thinking of the possibility of eradicating even national vices. Five years ago China and Great Britain made what is known as "the ten sears' agreement," by which the British government undertook to reduce the amount of opium sold in Calcutta on government account for export to China by 10 per cent every year until the traffic had ceased. On her part China agreed to diminish her own production in a corresponding way. Measures were to be taken to reduce the growth of opium in China 10 per cent each year until at the end of ten years no more would be raised. With supplies from India cut off and the home crop reduced and eventually suppressed altogether, the opium habit must necessarily disappear. The results accomplished thus far are promising, which is all the more remarkable because nearly every one prophesied failure, and the very missionaries who had carried on the crusade against opium for years sadly shook their heads, feeling that the great problem could not be solved in this simple way.

Travelers report that it is no longer common, as it was formerly, to see men smoking opium at their own doors. Even two years after the edict, those who smoked did so in secret. Dr. Cantlie quotes Lord William. Gascoyne-Cecil in his fascinating book "Changing China," who tells of the extraordinary difference that even two years made in the aspect of the land. On his first visit the country between Hankow and Harbin, as seen from the railway, was exquisite with the pink and white crops of poppy. On his next journey, nearly two years later, every poppy had disappeared. The dict is being enforced. The agricultural map of China shows after five years that there has been an actual reduction of 50 per cent in the production of opium. There has been as great a reduction in its use. This has been accomplished in spite of the fact that there were serious economic difficulties in the way. The small farmer nearly everywhere throughout China took up the cultivation of the poppy as a valuable "side line." Many grew only as much rice and as many vegetables as they used themselves; opium was the only product raised for the market. Opium is easily transported. A farmer could put the whole product of several fields on his back and sell it readily and profitably. The government deprived him of this source of income and the result has been a most favorable development in agriculture. In Yunnan, the province which formerly had the largest proportion of poppy growth, opium has given way to silk and cotton cultivation. In other districts the production of cereals has increased enormously. Particularly rice cultivation has grown in amount. Rice used to be imported, but enough is now raised in Chinese provinces to reduce the importation by several millions of dollars' worth.

All the world will watch with interest this other awakening of China, and the Oriental method of solving a great social question. In the West we have our social problems of a similar nature and China's example may prove illuminating and helpful.

Wre wish to call attention to the fact that we are in a pusition to render competent services in every branch ot patent or trade-mark work. Our staff is composed of mechanical, electrical and chemical experts, thoroughly trained to prepare and prosecute all patent applications, irrespective of the complex nature of the subfect matter involved, or of the specialized, technical, or scientific knowledge required therefor.

We are prepared to render opinions as to validity or infringement of patents, or with regard to conficts arising in trade-mark and unfair competition matters.

We also have associates throughout the world, who assist in the prosecution of patent and trade-mark applications filed in all countries foreign to the United States.

MUNN \& Co.

Patent Attornev.

361 Rroadway,

New York. N. Y

Branch Ofifce:

625 F Street, N. W.,

Washington, D. C

\section{SCIENTIFIC AMERICAN SUPPLEMENT} Founded 1876

NEW YORK, SATURDAY, DECEMBER 28, 1912

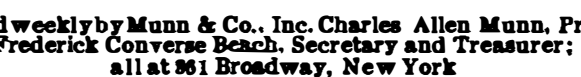

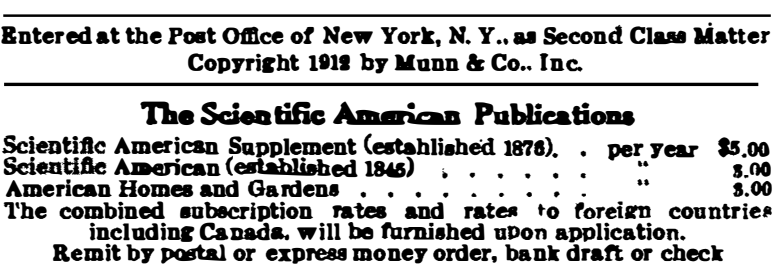

Munn \& Co., Inc., 361 Broadway, New York

The purpose of the Supplement is to publish the more important announcements of distin guished technologists, to digest significant arti. cles that appear in European publications, and altogether to reflect the most advanced thought in science and industry throughout the world.

Table of Contents

The Story of a Visit to Sir Henry Bessemer.-By S. T. ${ }^{\text {PAGE }}$

Sanitary Control of Public Eating and Drinking
Places.-By Walton Forest Dutton

Places.-By Walton Forest Dutton ..............
Manufacture of Manila Rope.-By C. W. Hunt.-15 Manufacture illustration

False Food Standards and the High Cost of Living.

The Removal of Ink from Waste Paper thods of Freak

egetable Ivory of Commerce

Its Elements-II-B - B Prof. H. A. Berntbsen

Texas-California Arc of Primary Triangulation.-By
William Bowie - 8 illustrations ................

Btigations of Chemical Reactions at High Pressure

ina Suppressing the Opium Habit

Index from July to December, 1912.—Vol. $74 \ldots \ldots \ldots$ 415-416 